\title{
Corporate Sustainability Reporting ${ }^{1}$
}

\author{
Dr.rer.nat. M. Fani Cahyandito \\ School of Management, Faculty of Economics, University of Padjadjaran \\ J1. Dipati Ukur 35 Bandung 40132 Indonesia \\ Tel/Fax.+62 22 2509055, Email: cahyandito@yahoo.com
}

\begin{abstract}
"Sustainability report is a public report by which companies provide internal and external stakeholders with a picture of corporate position and activities on economic, environmental and social dimensions" (WBCSD, 2002, "Sustainable development reporting - Striking a balance")
\end{abstract}

\section{Sustainability Reporting (SR)}

Producing an SR is not a spontaneous action. SR is a result of years of company experiences and activities in sustainable development. Demands for sustainability reporting are not only coming from company stakeholders (i.e. consumer, supplier, and investor) but also from the business associations and national governments. Against this background, it is not surprising, that the number of sustainability reports by companies is increasing worldwide

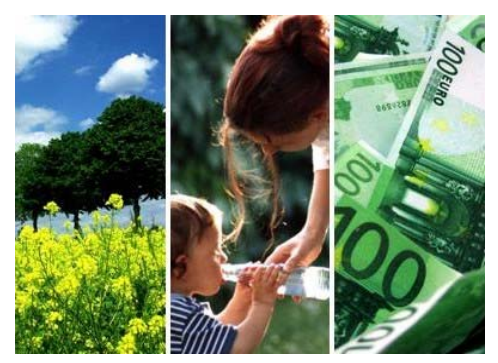
from year to year. Nowadays, SR is not only a trend to manage company image, but it is becoming a must for the company in showing transparency to support CSR programmes in maintaining a sound relationship and trust with all its stakeholders.

\section{Benefits of Sustainability Reporting}

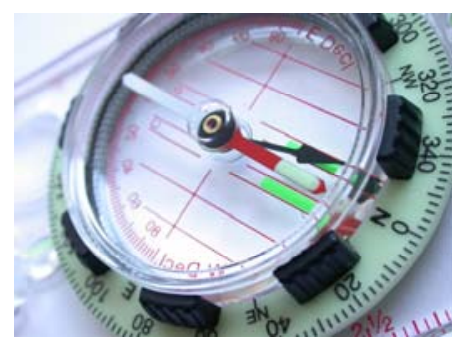

In short, sustainability reporting has various advantages: from raising staff awareness about the company's activities with regard to sustainable development to attracting long term capital and favourable financing conditions. Thus, the production of a report can be a benefit in itself. A report requires the company to take a more systematic approach to sustainable development and it becomes a part of the learning process within the organisation. Furthermore, a company can make use of the SR inter nally as an instrument to raise employees' awareness and working motivation, as well as to improve corporate management systems. Externally, SR can be used to show compliance to the regulations, raising company image, etc. The information of the SR is also useful to a wide range of internal and external stakeholders in making decisions regarding their involvement with a company. For instance, it can help them to assess management stewardship or accountability, decide whether to hold or sell their shares in the company, whether to become or remain an employee, or whether to start or continue to buy its products or services.

\footnotetext{
${ }^{1}$ Paper presented at the Asia-Europe Meeting (ASEM), Youth Dialogue 2007, Asia-Europe Strategic Choices for Equitable Development, 10-17 November 2007, Oriental Mindoro, Philippine.
} 


\section{Content and Publication of Sustainability Report}

Some think tank organizations worldwide have been developing SR guidelines in helping companies to create their own SR. The analysis of the documents of the Global Reporting Initiative (G3), CSR Europe (Communicating Corporate Sustainability Reporting), International Network for Environmental Management (The INEM Sustainability Reporting Guide) and WBCSD (Striking the Balance) showed that nine specific terms should be dealt with in a sustainability report:

- key figures/key indicators,

- table of contents,

- CEO statement,

- vision and strategy,

- company profile,

- company policy (corporate governance),

- management systems,

- stakeholder engagement, and

- performances.

As in the case of all information that is designed and released by a company itself, it may be that the public is suspicious of the sustainability reports, assuming that only positive facts are published and unfavourable facts are hidden. Consequently, one important precondition for successful sustainability reporting is trust. The report can only support the dialogue between the company and its stakeholders, if the contents and statements of the report are not doubted by the readers. Once this is accomplished the goals of sustainability reporting are achieved as well. Apart from the fact that companies should better follow the guidelines for sustainability reporting, there are various initiatives and approaches to make the report more trustworthy and transparent such as the inclusion of stakeholders' interest/needs, the inclusion of stakeholder comments' in the report, and the inclusion of verification statement from third (external) party in the report, etc.

A company must not only consider the content of the report, but SR must also be designed in such a way so that it attracts the attention of various stakeholders. In what form SR must be performed, whether in printed form, in a CD or in the web; how the information should be displayed, whether all in text format or in a table form or pictures/diagrams; how is the length of the report; how to distribute the report and how often SR must be publicated in certain period of time,

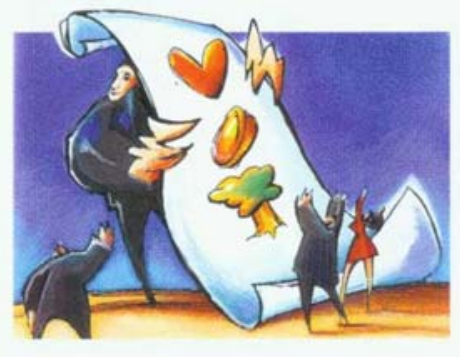
are some issues that must be taken into account in achieving the goal of sustainability reporting.

\section{Setting the Stage in Creating a Sustainability Report}

As has been mentioned previously, producing an SR is not an easy task. However, there are some stages that can be used as a foundation by a company to be able to create an SR as follows:

A. Build the Business Case

- Identify and obtain commitment from a senior management sponsor that will champion the sustainability reporting process

- Develop the business case for sustainability reporting for your company which: 
o Links to the strategic direction and priorities laid out by the company's Board and senior management

o Is consistent with the company's culture (e.g. values stated and lived by management and employees, emphasis on managing risks and striving for excellence)

o Reflects what drives corporate performance (e.g. maintaining or enhancing reputation, increasing short-term shareholder value, or emphasis on long term profitability and competitive position)

- Key elements of the business case can include:

Internal value:

o Attracting/retaining employees and motivating them

o Strengthening data collection and management

o Improving performance efficiency and effectiveness

o Providing broader performance information to senior management for stewardship (managing risks), and to the Board for oversight and strategy

External value:

o Contributing to community or national "license to operate"

o Enhancing corporate reputation

o Facilitating regulatory approvals

o Strengthening market access and share

B. Pre planning

- Make preliminary decisions on key reporting considerations by determining the:

o Type of report

o Level of integration among economic, environmental and social factors the report will aim to achieve

o Boundary of the report (what facilities, what organizations, and what time period?)

o Medium of reporting - printed or electronic

o Communications messaging and design of the report

o Level of verification or assurance to be used

C. Map out the Sustainability Reporting Process

- Organize a working group that includes representatives from a variety of different business units including environmental affairs, human resources, purchasing, product development, operations, finance, marketing and community or public relations

- Discuss sustainability and what it means to your company so the working group has a shared understanding

- Develop a process for managing sustainability reporting (e.g. some companies establish internal reporting procedures)

- Set responsibilities and reasonable time lines - share workload and responsibility

- Assign appropriate resources (external assistance in some areas may be required)

D. Identify Key Issues and Data Needs

- Identify the key issues the report will address

- Identify company specific key data that are already available (i.e. does staff satisfaction survey data exist? Does your company already have stakeholder input on key issues?)

- Look at the reports of other companies from around the world to generate ideas and collect examples

E. Stakeholder Engagement 
- Identify the key stakeholders the sustainability report will target

- Determine the extent of stakeholder engagement in the reporting process and at what stages:
a. Identification of issues to be included in the report
b. Development of key indicators of performance
c. Perceptions of company performance
d. Formal verification of company performance

- Undertake stakeholder engagement at the appropriate stages

F. Develop Performance Indicators

- Select appropriate and meaningful indicators

- Ensure that selected indicators make sense to your business and your stakeholders

G. Collect Information and Data

- Collect, collate and analyse relevant data and information

- Assess the reliability of data

- Collect data regularly and systematically and ensure that collection procedures guarantee data reliability

- Data sources can include: monitoring and measurement; regulatory reports; inventory and production records; financial and accounting records; purchasing records; environmental review, audit or assessment reports; environmental training records, etc.

H. Prepare and Design the Sustainability Report

- Identify key messages

- Formulate the text of the sustainability report

- Determine the appropriate report design, layout, and use of graphics

- $\quad$ Receive management sign off prior to printing

I. Verify and/or Assure

- Verify/assure the quality of the information and data (this can be done internally or through an external third party)

J. Publish, Distribute and Evaluate

- Publish the report either electronically or in printed format

- Determine dissemination strategy and disseminate the report to key stakeholders mechanisms to distribute or highlight your report can include: community meetings, annual general meetings, conferences and/or trade shows, press release, investor relations notices, advertising, email, reference on other forms of communication (i.e. customer bills)

- Evaluate the effectiveness of the report through feedback mechanisms (guidance provided under stakeholder engagement) and incorporate the feedback analysis into future reporting processes and into the ongoing management of sustainability issues

\section{Best Practice of Sustainability Report}

Some institutions such as Roberts Environmental Center at Claremont McKenna College California and Sustainability Ltd. London develop a methodology to enable them making ranking for the best published sustainability report. Below is an example from Sustainability Ltd on how they conduct the ranking process. 
The Global Reporters Survey has been conducted by SustainAbility Ltd. London with the aim to identify and classify best practice in sustainability reporting from around the world.

The 49 criteria cover:

- direct indications of a company's level of commitment (e.g. policies, use of stakeholders in identifying key issues, alignment of public policy activities with sustainability goals);

- direct indications of a company's performance (e.g. reporting on air emissions, ethical labor practices, community economic impacts);

- leading indications of a company's future performance (e.g. management systems, organisational accountability);

- indirect indications designed to illuminate aspects of performance not reported (e.g. scope of coverage, verification and assurance mechanisms).

Generally, the current methodology contains the same 49 criteria identified in 2000 (carried out also in 2004 and 2006's survey). The major change in 2002 was to make the scoring system more consistent across all areas, as explained in the box below.

In making the ranking of best sustainability reporting, the following processes are carried out:

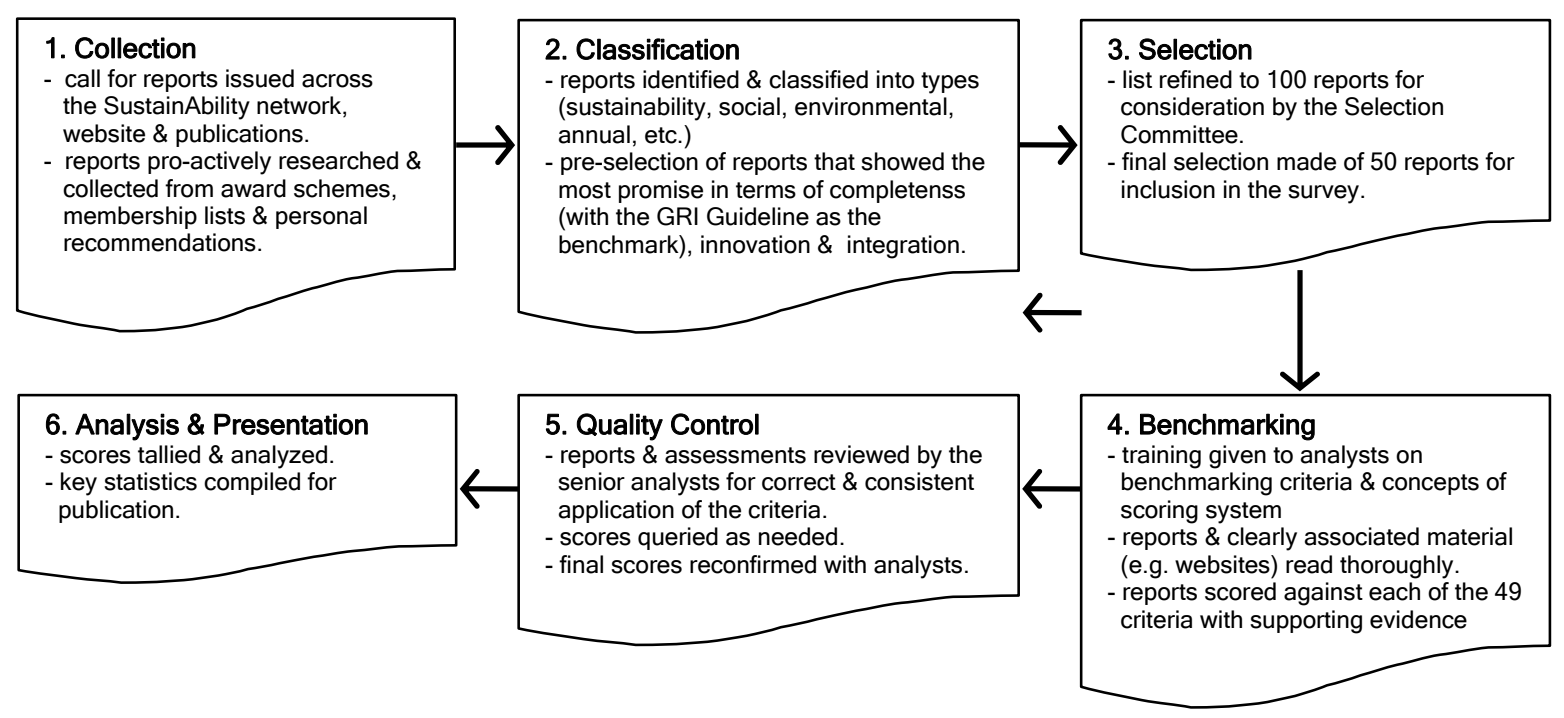

- Collection

The call for reports was issued across the SustainAbility Network, via our website, and through relevant publications. In addition, we looked for relevant reports and reporting processes through award schemes, membership lists and personal recommendations.

- Classification and pre -selection

The reports identified through these processes were then classified into types (e.g. sustainability, social, environmental, and annual). Selection by the Global Reporters team narrowed the field to just over 100 reports that already showed promise in terms of completeness, innovation and integration.

- Selection

The next step involved turning the shortlisted reports over to the Selection Committee (membership listed on page 22). The Committee made the final selection of the Top 50 reports for inclusion in the survey. 
- Benchmarking

Training was given to analysts on the benchmarking criteria and the scoring system.

The selected reports and clearly associated material (e.g. websites) were read

thoroughly - and the reports scored against each of the 49 criteria, with supporting

evidence cited by each analyst on company forms for later cross checking.

- Quality control

The reports and assessments were then reviewed by senior analysts, to ensure correct and consistent application of the criteria. Scores were queried if there appeared to be anomalies. The final scores were then reconfirmed with the analysts. All scores were tallied and analysed, and the key statistics compiled for publication.

\section{Result}

The series of international benchmark surveys produced since 2002 until 2006 by SustainAbility for the United Nations Environment Programme (UNEP) and Standard\&Poor's build directly on the work reported in the:

- Trust Us The Global Reporters 2002 Survey of Corporate Sustainability Reporting (published in 2002)

- Risk \& Opportunity Best Practice in Non Financial Reporting The Global Reporters 2004 Survey of Corporate Sustainability Reporting (published in 2004)

- Tomorrow's Value The Global Reporters 2006 Survey of Corporate Sustainability Reporting (published in 2006)

SustainAbility Ltd. And its partners, through the methodology and survey, were finally able to identify 50 top reports from around the world (the 'Top 50'), analyzing them in depth. It also spotlights another 50 reports (the 'Other 50') that offer further insights into where best practice in sustainability reporting is headed. Some of the trends in eight clusters of economic activity are explored in which seven 'hot topics', ranging from brands and reputation, through supply chain reporting to some of the ways companies are trying to address financial markets, were focused.

\section{References}

AccountAbility, 2003, AA 1000: Assurance Standard, London, Institute of Social and Ethical Accountability

Clausen, J., Loew, T., Klaffke, K., Raupach, M., Schoenheit, I., 2001, The INEM Sustainability Reporting Guide A Manual on Practical and Convincing Communication for Future oriented Companies, Berlin Hamburg, International Network for Environmental Management (INEM)

CorporateRegister, Global Report Output by Type, [Online] [cited 3 November 2007], URL $<:$ http://www.corporateregister.com/charts/Types\%20of\%20reports\%20published\% 20in\%202007.htm>

Corporate Social Responsibility (CSR), 2000, Communicating Corporate Social Respon sibility: Transparency, Reporting, Accountability - Voluntary Guidelines for Action, Belgium

Global Reporting Initiative (GRI), 2006, Sustainability Reporting Guidelines Version 3.0 (G3), Amsterdam

Standard\&Poor's/Sustainability/ UNEP, 2006, Tomorrow's Value The Global Reporters 2006 Survey of Corporate Sustainability Reporting 
Standard\&Poor's/Sustainability/ UNEP, 2004, Risk \& Opportunity Best Practice in Non Financial Reporting The Global Reporters 2004 Survey of Corporate Sustainability Reporting

Sustainability/UNEP, 2002, Trust Us The Global Reporters 2002 Survey of Corporate Sustainability Reporting 